\title{
Hypophosphatemia-Associated Respiratory Muscle Weakness in a General Inpatient Population
}

THOMAS R. GRAVELYN, M.D. NATHALIE BROPHY, M.D. CHRISTINE SIEGERT, R.R.T. MARC PETERS-GOLDEN, M.D. Ann Arbor, Michigan
From the Division of Pulmonary and Critical Care Medicine, University of Michigan and Veterans Administration Medical Centers, Ann Arbor, Michigan. Requests for reprints should be addressed to Dr. Marc Peters-Golden, Division of Pulmonary and Critical Care Medicine, University of Michigan Medical Center, 3916 Taubman Center, Ann Arbor, Michigan 48109. Manuscript submitted June 29,1987 , and accepted in revised form March 10, 1988.

\begin{abstract}
Although hypophosphatemia has been implicated as a cause of respiratory failure, its impact on respiratory muscle function in patients hospitalized for other reasons remains to be determined. Maximal inspiratory pressures (MIP) and maximal expiratory pressures (MEP) were measured at the bedside in $\mathbf{2 3}$ hospitalized patients with serum phosphate levels less than $2.5 \mathrm{mg} / \mathrm{dl}$, and these measurements were repeated daily during phosphate repletion until serum phosphate levels reached the normal range. A control group consisted of 11 normophosphatemic inpatients. Sixteen of 23 hypophosphatemic patients, but none of the control patients $(p<0.001)$, exhibited respiratory muscle weakness, defined as a MIP less than $40 \mathrm{~cm} \mathrm{H}_{2} \mathrm{O}$ or a MEP less than 70 $\mathrm{Cm} \mathrm{H}_{2} \mathrm{O}$. The mean initial MIP and MEP values were also significantly lower for the hypophosphatemic group. A significant correlation existed between Inltlal phosphate level and Inltlal MIP value $(r=0.50, p$ $<0.02$ ). With phosphate repletion, mean \pm SD MIP Increased from $-37 \pm 26 \mathrm{~cm} \mathrm{H}_{2} \mathrm{O}$ to $-49 \pm 24 \mathrm{~cm} \mathrm{H}_{2} \mathrm{O}(\mathrm{p}<0.003)$ and MEP from 60 $\pm 20 \mathrm{~cm} \mathrm{H} \mathrm{H}_{2} \mathrm{O}$ to $69 \pm 19 \mathrm{~cm} \mathrm{H}_{2} \mathrm{O}(\mathrm{p}<0.02)$. It is concluded that respiratory muscle weakness is common among hypophosphatemic patients and improves with phosphate repletion.
\end{abstract}

Hypophosphatemia has been implicated as a cause of reversible acute respiratory failure [1-3] and has recently been shown to impair the contractile properties of the diaphragm [4]. Unfortunately, information about hypophosphatemia-associated respiratory muscle weakness is limited to patients in respiratory failure [1-4]. The significance of an incidental finding of hypophosphatemia in patients without respiratory failure has not been examined. We undertook the current study to prospectively evaluate the incidence of respiratory muscle weakness in hospitalized hypophosphatemic patients using bedside measurements of respiratory muscle strength. In addition, we wished to determine if respiratory muscle weakness improves with phosphate repletion.

\section{PATIENTS AND METHODS}

Patients. Patients were recruited from the general medical and surgical services of the Ann Arbor Veterans Administration Medical Center during a 30-day study period. Patients were selected for study on the basis of serum phosphate levels as identified from daily clinical chemistry records. The normal range of serum phosphate levels in our laboratory is 2.5 to $4.5 \mathrm{mg} /$ dl. All patients with a serum phosphate level of less than $2.5 \mathrm{mg} / \mathrm{dl}$ were eligible for the hypophosphatemic study group. Patients with a normal serum phosphate level were eligible for the normophosphatemic control group. Patients with known neuromuscular disease or who were within one week of major surgery were excluded from the study. Discretion was used 
for the inclusion of critically ill patients and patients with cardiac dlsease, altered mental status, or psychlatrlc IIIness that could limit their ability to adequately perform the necessary pulmonary function tests. Informed consent was obtained from all subjects and this study was approved by the Committee on Human Studies of the Ann Arbor Veterans Administration Medical Center.

Fifty-four inpatients with hypophosphatemia were identified in the 30-day period during which the study was performed. After application of the just described exclusion criteria, 24 eligible patients consented to participate. One hypophosphatemic patient was subsequently excluded from the study because after one week of phosphate supplementation he had not achieved a normal serum phosphate level. On each of the first and last five days of the study period, two inpatients with normal serum phosphate levels were randomly selected from the clinical chemistry records for eligibility in the control group. After the exclusion criteria described earlier were applied, 11 normophosphatemic patients consented to participate, and these patients comprised the control group.

Protocol. Upon entry into the study, the patients' baseline respiratory muscle strength was assessed using maximal inspiratory pressures (MIP) and maximal expiratory pressures (MEP). Pressure measurements were determined from a dial manometer (R.F.M.D. Gauge, \#395946, OEM Medical Inc., Richmond, Virginia) connected to a plastic cylinder that was fitted on the proximal end with a rubber mouthpiece similar to that described by Black and Hyatt [5]. The dial manometer records a maximum negative pressure reading of $-80 \mathrm{~cm} \mathrm{H}_{2} \mathrm{O}$ and a maximum positive pressure reading of $80 \mathrm{~cm} \mathrm{H}_{2} \mathrm{O}$. Values exceeding the dial maxima were recorded as -80 or $80 \mathrm{~cm} \mathrm{H}_{2} \mathrm{O}$, respectively. Measurements were made while the patients were sitting and wearing a noseclip. MIP was measured at the end of a tidal expiration and MEP was measured at near total lung capacity. The pressures measured were maintained for at least one second and the best of three efforts was recorded. Reproducibility of these determinations was within 10 percent for all patients. Forced vital capacity (FVC) and forced expiratory volume in one second $\left(F E V_{1}\right)$ were measured using a portable digital spirometer (Eagle One, W.E. Collins Co., Braintree, Massachusetts). The best of three trials was recorded.

Hypophosphatemic patients were given supplemental phosphorus in the form of Neutra-Phos capsules, two capsules three times a day, until their serum phosphate level reached the normal range. Serum phosphate levels and MIP, MEP, FVC, and FEV 1 measurements were determined daily until a normal serum phosphate level was obtained. Control patients were not given Neutra-Phos capsules, but had daily measurements of serum phosphate, MIP, MEP, $\mathrm{FVC}$, and $\mathrm{FEV}_{1}$ for three days to assess the variability of these parameters and the possibility of a training effect as a cause of improvement in measured pulmonary function.

Patients were defined as "weak" if they had a MIP less than $40 \mathrm{~cm} \mathrm{H} \mathrm{H}_{2} \mathrm{O}$ or a MEP less than $70 \mathrm{~cm} \mathrm{H} \mathrm{H}_{2} \mathrm{O}$. These criteria were arbitrarily defined relative to published normal values in healthy adult men [5-7].

Hospital charts were reviewed to identify factors predis- posing to hypophosphatemia (intravenous dextrose infusion, total parenteral nutrltion, antacld therapy, respiratory alkalosis, and diabetic ketoacidosis, among others) and to determine concomitant electrolyte or metabolic abnormalities. In addition, because of the known ability of theophylline [8], systemic beta-adrenergics [9], and digitalis [10] to increase diaphragmatic contractility, use of these drugs was recorded.

Statistical Analysis. Chi-square analysis was used to assess the significance of differences between prevalences in the two groups. Initial serum phosphate, MIP, MEP, FVC, and $F E V_{1}$ measurements were compared between hypophosphatemic and control patients using the upaired Student t-test. The correlation between MIP measurements and serum phosphate levels was assessed with linear regression. Measurements of serum phosphate, respiratory muscle strength, and ventilatory function were compared preand post-phosphate repletion with the paired Student t-test. The same measurements were compared in control patients at the beginning and end of their three-day trial. A p value of $<0.05$ was considered significant. All data are expressed as mean $\pm S D$.

\section{RESULTS}

During the study period, 1,939 serum phosphate determinations were processed by the laboratory, 137 (7.1 percent) of which were less than $2.5 \mathrm{mg} / \mathrm{dl}$. These 137 values originated from 92 patients, 54 of them inpatients. There were 1,145 inpatients at the Ann Arbor Veterans Administration Medical Center during the study period for a 4.7 percent overall prevalence of hypophosphatemia among inpatients.

Table I shows the ages, duration of hospitalization at entry, and the major active diagnoses during the study period for all patients studied. There were no significant differences in age or the duration of hospitalization prior to study entry in the two groups. There were two women in the hypophosphatemic group and none in the normophosphatemic group. Two of the hypophosphatemic patients required mechanical ventilation, one for chronic obstructive pulmonary disease with respiratory failure and the second for gastrointestinal bleeding. There were no other significant metabolic abnormalities or any abnormalities in serum potassium, sodium, calcium, or magnesium levels found in any patient during the study period. A predisposing risk factor for hypophosphatemia could be identified in 20 of 23 hypophosphatemic patients and in eight of 11 normophosphatemic patients. The two most common factors found among all patients were antacid therapy (20 patients) and intravenous dextrose infusion (11 patients).

The mean initial serum phosphate level for the hypophosphatemic patients was $1.9 \pm 0.4 \mathrm{mg} / \mathrm{dl}$ as compared with a value of $3.6 \pm 0.5 \mathrm{mg} / \mathrm{dl}(\mathrm{p}<0.00001)$ for the normophosphatemic control patients. By the criteria utilized, respiratory muscle weakness was found in 16 of 23 hypophosphatemic patients and none of the 11 control 


\begin{tabular}{|c|c|c|c|}
\hline Patient & Age* & $\begin{array}{c}\text { Days Hospitalized } \\
\text { at Entry* }\end{array}$ & Major Active Diagnoses \\
\hline \multicolumn{4}{|c|}{ Hypophosphatemic } \\
\hline 1 & 71 & 1 & Syncope; history of pulmonary embolism \\
\hline 2 & 71 & 2 & Upper gastrointestinal bleed \\
\hline 3 & 61 & 1 & COPD exacerbation; cor pulmonale \\
\hline 4 & 67 & 1 & Red cell aplasia; chest pain; atrial fibrillation \\
\hline 5 & 62 & 10 & Post-abdominal aortic aneurysm resection; COPD \\
\hline 6 & 51 & 2 & Alcohol withdrawal \\
\hline 7 & 57 & 2 & Cellulitis; Crohn's disease \\
\hline 8 & 64 & 90 & COPD; Parkinson's disease; diabetes mellitus \\
\hline 9 & 76 & 4 & Occipital lobe infarction; history of asthma \\
\hline 10 & 62 & 19 & Acute myelocytic leukemia \\
\hline 11 & 54 & 34 & Tuberculosis; history of esophageal carcinoma \\
\hline 12 & 48 & 3 & Alcoholic hepatitis; ascites \\
\hline 13 & 58 & 10 & Histiocytic lymphoma; streptococcal sepsis \\
\hline 14 & 58 & 4 & Post-resection of colon cancer \\
\hline 15 & 45 & 9 & Chronic diarrhea and weight loss \\
\hline 16 & 58 & 23 & Pneumonia; metastatic lung cancer \\
\hline 17 & 65 & 27 & Cholangitis \\
\hline 18 & 65 & 3 & COPD exacerbation \\
\hline 19 & 61 & 4 & Obstructive jaundice \\
\hline 20 & 84 & 2 & Cerebrovascular accident \\
\hline 21 & 86 & 10 & Deep venous thrombosis \\
\hline 22 & 77 & 23 & Upper gastrointestinal bleed; carcinoma of tongue \\
\hline 23 & 62 & 2 & Respiratory arrest; COPD exacerbation \\
\hline Mean & 63 & 12.4 & \\
\hline SD & 10 & 19.2 & \\
\hline \multicolumn{4}{|c|}{ Normophophosphatemlc } \\
\hline 1 & 70 & 8 & Congestive failure \\
\hline 2 & 41 & 29 & Psoriasis; sleep apnea \\
\hline 3 & 70 & 5 & Chest pain \\
\hline 4 & 55 & 9 & Hemoptysis; new diagnosis of lung cancer \\
\hline 5 & 21 & 1 & Chemotherapy for astrocytoma \\
\hline 6 & 64 & 2 & Psoriasis; diabetes mellitus \\
\hline 7 & 66 & 6 & Congestive failure; diabetes mellitus; arrhythmias \\
\hline 8 & 53 & 2 & Scleroderma; cor pulmonale \\
\hline 9 & 59 & 3 & Chest pain \\
\hline 10 & 62 & 9 & Mediastinal mass; history of cirrhosis \\
\hline 11 & 68 & 20 & Congestive failure \\
\hline Mean & 57 & 8.5 & \\
\hline $\mathrm{SD}$ & 15 & 8.2 & \\
\hline
\end{tabular}

COPD = chronic obstructive pulmonary disease.

* There were no differences in mean age or days hospitalized at entry between the two groups.

patients $(p<0.001)$. The mean initial MIP value of the hypophosphatemic patients was significantly lower ( $p$ $<0.03$ ) than that of the normophosphatemic control patients $\left(-37 \pm 26 \mathrm{~cm} \mathrm{H}_{2} \mathrm{O}\right.$ versus $-57 \pm 16 \mathrm{~cm} \mathrm{H}_{2} \mathrm{O}$, respectively) (Figure 1). In similar fashion, the mean initial MEP value of the hypophosphatemic patients was significantly lower $(p<0.006)$ than that of the control patients $\left(60 \pm 20 \mathrm{~cm} \mathrm{H} \mathrm{H}_{2} \mathrm{O}\right.$ versus $78 \pm 6 \mathrm{~cm} \mathrm{H} \mathrm{H}_{2} \mathrm{O}$, respectively) (Figure 2). There was no significant difference in mean FVC or FEV measurements between the hypophosphatemic patients and the control patients (FVC: $2.47 \pm 1.1$ liters versus $2.89 \pm 1.01$ liters, respectively, and $\mathrm{FEV}_{1}: 1.76 \pm 0.83$ liters versus $2.34 \pm$
0.91 liters, respectively). Arterial blood gases were obtained for routine clinical indications in eight of the hypophosphatemic patients; the highest partial carbon dioxide pressure recorded was $42 \mathrm{~mm} \mathrm{Hg}$.

There appeared to be a relationship between the degree of hypophosphatemia and the degree of respiratory muscle weakness when initial MIP measurements were plotted as a function of initial serum phosphate concentration $(r=0.50, p<0.02)$ (Figure 3). Of the 12 patients with phosphate levels less than or equal to $2.0 \mathrm{mg} / \mathrm{dl}$, nine demonstrated respiratory muscle weakness by our criteria. The four patients with serum phosphate levels below $1.5 \mathrm{mg} / \mathrm{dl}$ all had MIP values below or equal to 20 
$\mathrm{cm} \mathrm{H}_{2} \mathrm{O}$. When all serum phosphate and MIP values recorded in both groups during the entire study period were considered, a weaker but still significant correlation between phosphate and MIP persisted $(r=0.28, n=$ 106, $p<0.02)$.

With phosphate repletion, the mean serum phosphate level increased in the hypophosphatemic patients from $1.9 \pm 0.4 \mathrm{mg} / \mathrm{dl}$ to $3.5 \pm 0.8 \mathrm{mg} / \mathrm{dl}$ ( $\mathrm{p}<0.00001$ ). Hypophosphatemic patients were repleted in $2.0 \pm 1.3$ days. The mean initial serum phosphate level of the control patients was $3.6 \pm 0.5 \mathrm{mg} / \mathrm{dl}$ and was $3.6 \pm 0.6$ $\mathrm{mg} / \mathrm{dl}$ on the third day of the study. With phosphate repletion, the mean MIP value in the hypophosphatemic patient group increased from $-37 \pm 26 \mathrm{~cm} \mathrm{H}_{2} \mathrm{O}$ to -49 $\pm 24 \mathrm{~cm} \mathrm{H} \mathrm{H}_{2} \mathrm{O}(\mathrm{p}<0.003$ ). For the normophosphatemic patient group, the mean initial MIP value was $-57 \pm 16$ $\mathrm{cm} \mathrm{H}_{2} \mathrm{O}$ and was $-55 \pm 15 \mathrm{~cm} \mathrm{H}_{2} \mathrm{O}$ after three days of testing ( $p=N S$ ). In similar fashion, there was a significant increase in the mean MEP measurement in the hypophosphatemic patients that was not seen in the normophosphatemic control patients $\left(60 \pm 20 \mathrm{~cm} \mathrm{H}_{2} \mathrm{O}\right.$ to $69 \pm 19$ $\mathrm{cm} \mathrm{H} \mathrm{H}_{2} \mathrm{O}, \mathrm{p}<0.02$, and $78 \pm 6 \mathrm{~cm} \mathrm{H} \mathrm{H}_{2}$ to $77 \pm 7 \mathrm{~cm}$ $\mathrm{H}_{2} \mathrm{O}, \mathrm{p}=\mathrm{NS}$, respectively). There were no significant differences in the FVC and FEV 1 measurements pre- and post-phosphate repletion in the hypophosphatemic patients (FVC: $2.47 \pm 1.11$ liters versus $2.50 \pm 1.02$ liters respectively, and $\mathrm{FEV}_{1}: 1.76 \pm 0.83$ liters versus $1.81 \pm$ 0.86 liters, respectively). Similarly, there were no changes in FVC and FEV 1 after three days of testing in the normophosphatemic control patients (FVC: $2.89 \pm 1.01$ liters versus $2.77 \pm 0.89$ liters, respectively, and $\mathrm{FEV}_{1}$ : $2.34 \pm 0.91$ liters versus $2.15 \pm 0.84$ liters, respectively). No patients in either group received beta-adrenergic agents. One hypophosphatemic patient and two normophosphatemic patients were receiving digitalis at entry. Theophylline was used by four hypophosphatemic and two normophosphatemic patients at entry and continued during the study period in all of them. In only one hypophosphatemic patient was theophylline therapy instituted during the study period (Patient 1).

There was no significant difference between the mean MIP value of the hypophosphatemic patients after phosphate repletion $\left(-49 \pm 24 \mathrm{~cm} \mathrm{H}_{2} \mathrm{O}\right)$ and that obtained after three days of testing in the normophosphatemic control patients $\left(-55 \pm 15 \mathrm{~cm} \mathrm{H}_{2} \mathrm{O}\right)$. There was also no significant difference between the mean MEP value in the hypophosphatemic patients following repletion ( $69 \pm 19$ $\mathrm{cm} \mathrm{H}_{2} \mathrm{O}$ ) and that in the normophosphatemic patients on Day $3\left(77 \pm 7 \mathrm{~cm} \mathrm{H} \mathrm{H}_{2} \mathrm{O}\right)$.

\section{COMMENTS}

Our study corroborates previous estimates of the frequency of hypophosphatemia in an adult inpatient population, and for the first time documents an increased incidence of respiratory muscle weakness in these patients using simple measurements at the bedside. Furthermore, we have

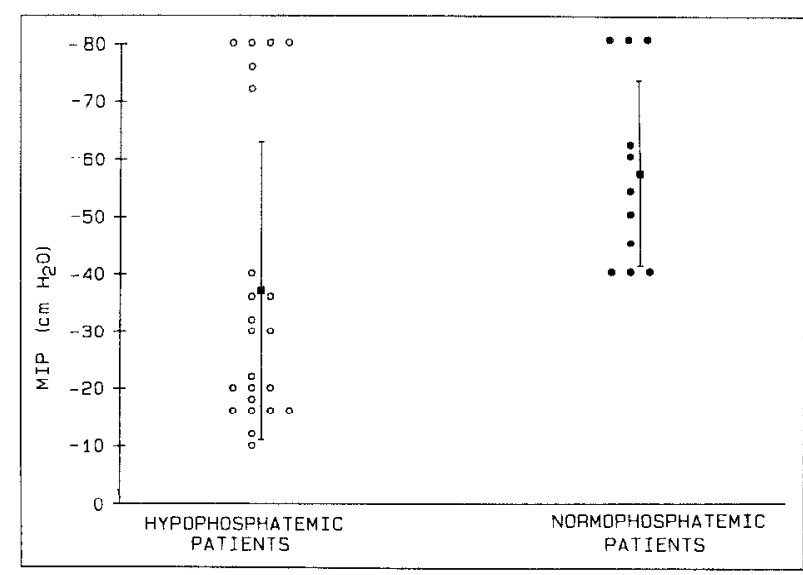

Figure 1. MIP values for the hypophosphatemic patients and the normophosphatemic control patients. Note that pressures greater than $-80 \mathrm{~cm} \mathrm{H}_{2} \mathrm{O}$ are listed at $-80 \mathrm{~cm}$ $\mathrm{H}_{2} \mathrm{O}$. Mean $\pm S D$ values for the respective groups are indicated.

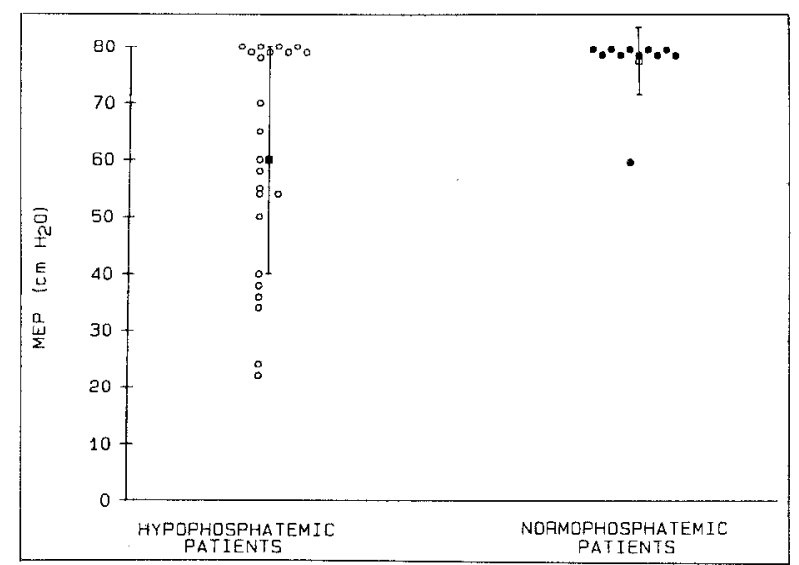

Figure 2. MEP values for the hypophosphatemic patients and the normophosphatemic control patients. Note that pressures greater than $80 \mathrm{~cm} \mathrm{H}_{2} \mathrm{O}$ are listed at $80 \mathrm{~cm} \mathrm{H}_{2} \mathrm{O}$. Mean $\pm S D$ values for the respective groups are indicated.

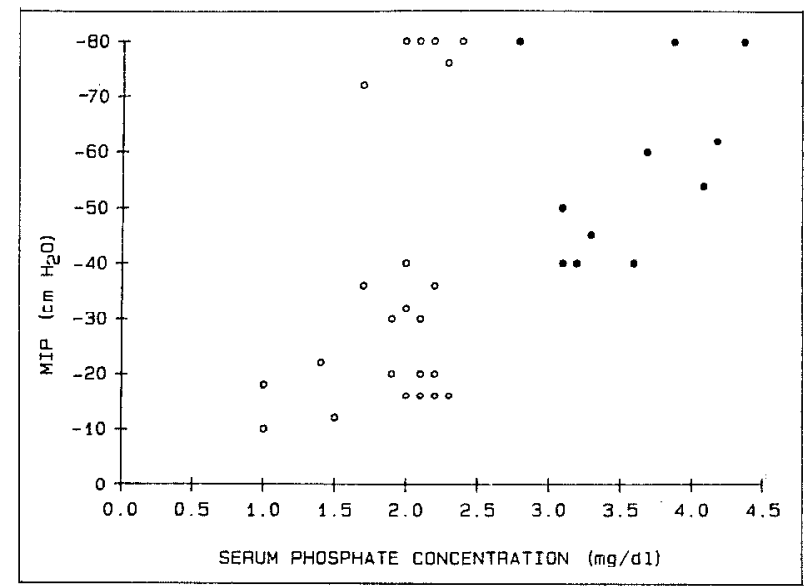

Figure 3. MIP values at entry plotted as a function of initial serum phosphate concentrations for the hypophosphate mic patients $(O)$ and the normophosphatemic control patients $(\bullet) .(r=0.50, p<0.02)$. 
demonstrated that with phosphate repletion, respiratory muscle strength improves to the level found in normophosphatemic control patients.

Previous studies have shown that hypophosphatemia is not an uncommon finding in an adult inpatient population and our prevalence figure of 4.7 percent if similar to that reported by others $[11,12]$. It should be noted that because serum phosphate determinations may not have been performed on every inpatient, our prevalence figure represents an approximation. The prevalence of hypophosphatemia increases in those patients receiving antacids or intravenous dextrose, in patients with diabetic ketoacidosis, in patients withdrawing from alcohol, and in patients with a respiratory illness [11-13]. Similar predisposing factors were seen in this study.

MIP and MEP measurements were selected as indicators of respiratory muscle strength because of their sensitivity and simplicity $[7,14]$. Our study has confirmed the fact that spirometric measurements, in contrast, are relatively insensitive indicators of respiratory muscle weakness [14]. The manometer used in this study was designed to accurately show small changes in positive or negative pressure, but had the inherent limitation of a maximum pressure reading of + or $-80 \mathrm{~cm} \mathrm{H}_{2} \mathrm{O}$. As shown in Figures 1 and 2, this underestimated the true values in several patients in both groups. This limitation, however, tended to bias the data against demonstrating improvement in MIP and MEP values after phosphate repletion in the hypophosphatemic patients: three hypophosphatemic patients increased their MIP from a value below $-80 \mathrm{~cm} \mathrm{H}_{2} \mathrm{O}$ to a value greater than $-80 \mathrm{~cm} \mathrm{H}_{2} \mathrm{O}$ as compared with one normophosphatemic patient after three days of testing. Seven hypophosphatemic patients increased their MEP from a value less than $80 \mathrm{~cm} \mathrm{H}_{2} \mathrm{O}$ to a value greater than $80 \mathrm{~cm} \mathrm{H}_{2} \mathrm{O}$ as compared to one normophosphatemic patient. Using a manometer with the same sensitivity and a greater range would change the mean values for MIP and MEP reported herein and would be expected to show a greater increase in respiratory muscle strength with phosphate repletion.

We chose to measure MIP at near functional residual capacity rather than at residual volume because this is the lung volume at which tidal breathing occurs [7]. There is only one prior report of normal values for MIP at functional residual capacity where measurements ranged from -40 $\mathrm{cm} \mathrm{H}_{2} \mathrm{O}$ to greater than $-180 \mathrm{~cm} \mathrm{H}_{2} \mathrm{O}$ with a mean of $-78.8 \mathrm{~cm} \mathrm{H} \mathrm{H}_{2} \mathrm{O}$ [6]. We therefore chose to define weakness conservatively as a MIP less than $-40 \mathrm{~cm} \mathrm{H}_{2} \mathrm{O}$. There is some variability in the reported normal range for MEP values in healthy adult men, with a suggested lower limit of normal of approximately $100 \mathrm{~cm} \mathrm{H} \mathrm{H}_{2} \mathrm{O}[5,7,15]$. We arbitrarily chose a value of $70 \mathrm{~cm} \mathrm{H} \mathrm{H}_{2} \mathrm{O}$ or less to define weakness. Using these criteria, we found 16 of 23 hypophosphatemic patients to evidence measurable respiratory muscle weakness as compared with zero of 11 normophosphatemic control patients. There also appeared to be a relationship between the degree of hypophosphatemia and the degree of respiratory muscle weakness at entry as illustrated by Figure 3, and throughout the study, when MIP measurements were plotted as a function of phosphate concentration. The weakest patients had the lowest serum phosphate levels. With phosphate repletion, mean MIP and MEP values were no longer significantly different from normophosphatemic control values.

Although we did not specifically match hypophosphatemic and normophosphatemic patients for severity of illness, selection on the basis of phosphate levels from daily clinical chemistry records should have minimized any bias in favor of noncomparability between the two groups. Indeed, the major diagnoses listed in Table I suggest comparable severities of illness between them. Moreover, as patients were not necessarily entered into the study on admission to the hospital (mean duration of hospitalization upon entry greater than one week for both groups), it is unlikely that the hypophosphatemic patients were more acutely ill at entry. Finally, patients who were uncooperative and unable to perform the tests were excluded, and the high level of reproducibility in MIP and MEP values recorded strongly suggests that patients in the two groups were cooperative to a similar degree.

For a number of reasons, we believe that respiratory muscle weakness was a function of hypophosphatemia, and that improvement was due to phosphate repletion: (1) As just indicated, we do not believe that the apparent respiratory muscle weakness in the hypophosphatemic patients can be explained merely by the fact that they were sicker and less able to cooperate. (2) A significant correlation existed between initial phosphate levels and initial MIP values. (3) No other electrolyte or metabolic abnormalities existed that might explain the weakness observed. (4) Although hypercapnia has been reported to impair diaphragmatic function [16], none of the eight hypophosphatemic patients on whom arterial blood gas measurements were available exhibited hypercapnia. (5) Improvement in MIP and MEP values with phosphorus repletion occurred wlthin 48 hours in most of the hypophosphatemic patients, too rapid to be accounted for by changes in overall nutritional status. (6) There were no significant changes in spirometric values pre- and postrepletion, effectively excluding changes in obstructive airways disease or resolving acute bronchopulmonary disease as the cause for the improvement in respiratory muscle strength. (7) In only one hypophosphatemic patient was treatment with a drug known to increase diaphragmatic contractility (theophylline) initiated during the study period. This, along with the fact that the hypophosphatemic patients exhibited improvements in MEP (reflecting predominantly skeletal muscle function) as well as MIP (reflecting predominantly diaphragmatic function), 
rule out the possibility that the observed improvements were attributable to drug therapy. (8) Finally, serial testing in normophosphatemic patients revealed no "training effect" that might itself account for the improvement in MIP and MEP values observed in the hypophosphatemic patients.

Although our results unequivocally demonstrate respiratory muscle weakness in the hypophosphatemic patients as compared with the normophosphatemic patients, marked variability in MIP and MEP values was observed in the former. This most likely reflects the multiple determinants of respiratory muscle function, including not only phosphate level, but also serum potassium [17] and magnesium levels [18], acid-base status $[16,19]$, nutritional status $[20]$, oxygen delivery to the respiratory muscles $[21,22]$, and length-tension relationships of the muscles $[21,22]$. Given that serum phosphate is only one of many factors that influence respiratory muscle function, it is not surprising that the correlation between phosphate level and MIP in our study was stronger when only initial (lower) phosphate values, rather than all values, were considered. The mechanism responsible for respiratory muscle weakness in hypophosphatemia is thought to be the diminution in the supply of high-energy phosphate compounds necessary for muscle contraction, and/or a reduction in the supply of 2,3-diphosphoglycerate leading to tissue hypoxia [23,24]. Although other factors must be corrected when identified, hypophosphatemia is easily reversible if recognized and treated appropriately.

The importance of recognizing hypophosphatemia-associated respiratory muscle weakness is obvious in the patient with acute respiratory failure who cannot be weaned from mechanical ventilation. Recognizing occult respiratory muscle weakness has several important implications. Early recognition of hypophosphatemia-associated respiratory muscle weakness may allow repletion and improvement in respiratory muscle function before acute respiratory failure develops. Our hypophosphatemic patients as a group demonstrated severe respiratory muscle weakness with a mean MIP of $-37 \mathrm{~cm} \mathrm{H}_{2} \mathrm{O}$. To place this value in perspective, a recent edition of one major pulmonary textbook lists a MIP value less than -25 $\mathrm{cm} \mathrm{H}_{2} \mathrm{O}$ as one criterion for instituting mechanical ventilation [25]. In addition, MEP, which was significantly impaired in the hypophosphatemic group, is an important determinant of an effective cough. An impaired cough may result in retained secretions, which may increase the patient's susceptibility to a nosocomial respiratory infection.

Although hypophosphatemia has been implicated as the cause of acute respiratory failure in case reports, the prevalence of occult respiratory muscle weakness in hypophosphatemic patients without acute respiratory failure has not previously been evaluated in a prospective manner. We have demonstrated that respiratory muscle weakness is a common occurrence in hospitalized patients with incidentally detected hypophosphatemia and that the degree of respiratory muscle weakness can be severe. With phosphate repletion, respiratory muscle weakness improves.

\section{ACKNOWLEDGMENT}

We wish to thank Rose Welcome and Sharon Waltz for typing the manuscript and Susan J. Winston, M.D., for technical assistance.

\section{REFERENCES}

1. Newman JH, Neff TA, Ziporin P: Acute respiratory failure associated with hypophosphatemia. N Engl J Med 1977; 296: 1101-1103.

2. Agusti AGN, Torres A, Estopa R, Agustividal A: Hypophosphatemia as a cause of failed weaning: the importance of metabolic factors. Crit Care Med 1984; 12: 142143.

3. Youssef HAE: Hypophosphatemic respiratory failure complicating total parenteral nutrition: a potentially lethal iatrogenic hazard. Int Surg 1982; 67: 371-372.

4. Aubier $M$, Murciano $D$, Lecocguic $Y$, Viires $N$, Jacquens $Y$, Squara $P$, Pariente R: Effect of hypophosphatemia on diaphragmatic contractility in patients with acute respiratory failure. N Engl J Med 1985; 313: 420-424

5. Black LF, Hyatt RE: Maximal respiratory pressures: normal values and relationship to age and sex. Am Rev Respir Dis 1969; 99: 696-702.

6. Sharp JT, Van Lith P, Nuchprayoon CV, Briney R, Johnson FN: The thorax in chronic obstructive lung disease. Am J Med 1968; 44: 39-46.
7. Clausen JL: Maximal inspiratory and expiratory pressures. In: Clausen $\mathrm{JL}$, ed. Pulmonary function testing: guidelines and controversies. San Francisco: Grune and Stratton, $1984 ; 187-191$

8. Aubier M, DeTroyer A, Sampson M, Macklem PT, Roussos C: Aminophylline improves diaphragmatic contractility. $\mathbf{N}$ Engl J Med 1981; 305: 249-252.

9. Aubier M, Viires N, Murciano D, Medrano G, Lecocguic $Y$, Pariente R: Effects and mechanism of action of terbutaline on diaphragmatic contractility and fatigue. J App Physiol 1984; 56: 922-929.

10. Aubier M, Murciano D, Viires N, et al: Effects of digoxin on diaphragmatic strength generation in patients with chronic obstructlve pulmonary disease during acute respiratory failure. Am Rev Respir Dis 1987; 135: 544-548.

11. Fisher J, Magid N, Kallman C, et al: Respiratory illness and hypophosphatemia. Chest 1983; 83: 504-508.

12. Betro MG, Pain RW: Hypophosphatemia and hyperphosphatemia in a hospital population. Br Med J 1972; 1: 273276. 
13. Juan D, Elrazak MA: Hypophosphatemia in hospitalized patients. JAMA 1979; 242: 163-164.

14. Black LF, Hyatt RE: Maximal static respiratory pressures in generalized neuromuscular disease. Am Rev Respir Dis 1971; 103: 641-650.

15. Gilbert $\mathrm{R}$, Auchincloss $\mathrm{JH}$, Bleb $\mathrm{S}$ : Measurement of maximum inspiratory pressure during routine spirometry. Lung 1978; 155: 23-32.

16. Juan G, Calverley P, Talamo C, Schnader J, Roussos C: Effect of carbon dioxide on diaphragmatic function in human beings. N Engl J Med 1984; 310: 874-879.

17. Herrmann RA, Mead AW, Spritz N, Rubin AL: Hypopotassemia with respiratory paralysis. Case due to renal tubular acidosis. Arch Intern Med 1961; 108: 925-928.

18. Molloy DW, Dhingra S, Solven F, Wilson A, McCarthy DS: Hypomagnesmia and respiratory muscle power. Am Rev Respir Dis 1984; 129: 497-498.

19. Fitzgerald RS, Garfinkel F, Silbergeld E, Loscutoff SC: Factors in the interpretation of mouth occlusion pressure during measurements of chemosensitivity. Chest 1976; 70: 145-149.

20. Arora NS, Rochester DF: Respiratory muscle strength and maximal voluntary ventilation in undernourished patients. Am Rev Respir Dis 1982; 126: 5-8.

21. Roussos C, Macklem PT: The respiratory muscles. N Engl J Med 1982; 307: 786-797.

22. Rochester DF: The diaphragm: contractile properties and fatigue. J Clin Invest 1985; 75: 1397-1402.

23. Lichtman MA, Miller DR, Cohen J, Waterhouse C: Reduced red cell glycolysis 2,3-diphosphoglycerate and adenosine triphosphate concentration and increased hemoglobinoxygen affinity caused by hypophosphatemia. Ann Intern Med 1971; 74: 562-568.

24. Staff JS: Phosphate homeostasis and hypophosphatemia. Am J Med 1982; 72: 489-495.

25. Pierce AK: Acute respiratory failure. In: Guenter $\mathrm{CA}$, Welch $\mathrm{MH}$, eds. Pulmonary medicine, 2nd ed. Philadelphia: JP Lippincott, 1982; 238. 